\title{
A pilot study on the feasibility of European harmonized Human Biomonitoring: Strategies towards a common approach, challenges and opportunities
}

L. Casteleyn ${ }^{\text {a,* }}$, B. Dumez ${ }^{\text {a }}$, K. Becker ${ }^{\mathrm{b}}$, M. Kolossa-Gehring $^{\mathrm{b}}$, E. Den Hond ${ }^{\mathrm{c}}$, G. Schoeters $^{\mathrm{c}}$, A. Castaño ${ }^{\text {d }}$, H.M. Koch ${ }^{\mathrm{e}}$, J. Angerer ${ }^{\mathrm{e}}$, M. Esteban ${ }^{\mathrm{d}}$, K. Exley ${ }^{\mathrm{f}}$, O. Sepai ${ }^{\mathrm{f}}$, L. Bloemen ${ }^{\mathrm{g}}$, M. Horvat ${ }^{\text {h }}$, L.E. Knudsen ${ }^{i}$, A. Joas ${ }^{j}$, R. Joas ${ }^{j}$, P. Biot ${ }^{k}$, G. Koppen ${ }^{c}$, M-C. Dewolf ${ }^{y}$, A. Katsonouri ${ }^{1}$, A. Hadjipanayis ${ }^{\mathrm{m}}$, M. Cerná ${ }^{\mathrm{n}}$, A. Krsková $^{\mathrm{n}}, \mathrm{G}$. Schwedler ${ }^{\mathrm{c}}$, U. Fiddicke ${ }^{\mathrm{c}}$, J.K.S. Nielsen ${ }^{i}$, J.F. Jensen ${ }^{i}$, P. Rudnai ${ }^{\circ}$, S. Közepésy ${ }^{\circ}$, M. Mulcahy ${ }^{\mathrm{p}}$, R. Mannion ${ }^{\mathrm{p}}{ }$, A.C. Gutleb ${ }^{\mathrm{q}}$, M.E. Fischer ${ }^{\mathrm{r}}$, D. Ligocka ${ }^{\mathrm{s}}$, M. Jakubowski ${ }^{\mathrm{s}}$, M.F. Reis ${ }^{\mathrm{t}}$, S. Namorado ${ }^{\mathrm{t}}$, I-R. Lupsa ${ }^{\text {u }, ~ A . E . ~ G u r z a u ~}{ }^{\text {u, }}$ K. Halzlova ${ }^{\text {v }}$, M. Jajcaj ${ }^{\text {, }}$, D. Mazej ${ }^{\text {h }}$, J. Tratnik Snoj ${ }^{\text {h }}$, M. Posada ${ }^{\text {d }}$, E. López ${ }^{\mathrm{d}}$, M. Berglund ${ }^{\mathrm{w}}$, K. Larsson ${ }^{\mathrm{w}}$, A. Lehmann ${ }^{\mathrm{x}}$, P. Crettaz ${ }^{\mathrm{x}}$, D. Aerts ${ }^{\mathrm{k}}$

${ }^{a}$ KU Leuven, Belgium

${ }^{\mathrm{b}}$ Federal Environment Agency (UBA), Germany

${ }^{\mathrm{C}}$ VITO, Belgium

' Instituto de Salud Carlos III, Spain

e Ruhr Universität Bochum, Germany

${ }^{\mathrm{f}}$ Public Health England, United Kingdom

${ }^{\mathrm{g}}$ Environmental Health Sciences International, The Netherlands

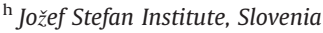

${ }^{\mathrm{i}}$ Kobenhavns Universitet, Denmark

${ }^{\mathrm{j}}$ BiPRO, Germany

${ }^{\mathrm{k}}$ Federal Public Service Health, Food chain safety and Environment, Belgium

${ }^{1}$ State General Laboratory, Cyprus

${ }^{\mathrm{m}}$ Larnaca Hospital, Cyprus

${ }^{\mathrm{n}}$ National Institute of Public Health, Czech Republic

${ }^{\circ}$ National Institute of Environmental Health, Hungary

${ }^{\mathrm{p}}$ Health Service Executive, Ireland

${ }^{\mathrm{q}}$ Centre de Recherche Public - Gabriel Lippmann, Luxembourg

${ }^{\mathrm{r}}$ Laboratoire National de Santé, Luxembourg

${ }^{s}$ Nofer Institute of Occupational Medicine, Poland

${ }^{\mathrm{t}}$ Faculdade de Medicina de Lisboa, Portugal

${ }^{u}$ Environmental Health Center, Romania

${ }^{v}$ Urad Verejneho Zdravotnictva Slovenskej Republiky, Slovakia

${ }^{\mathrm{w}}$ Institute of Environmental Medicine, Karolinska Institutet, Stockholm, Sweden

${ }^{x}$ Federal Office of Public Health (FOPH), Switzerland

${ }^{\mathrm{y}}$ Hainaut Vigilance Sanitaire (HVS) and Hygiene Publique in Hainaut (HPH), Belgium

\section{A R T I C L E I N F O}

\section{Article history:}

Received 23 May 2014

Received in revised form

21 October 2014

Accepted 27 October 2014

\begin{abstract}
A B S T R A C T
In 2004 the European Commission and Member States initiated activities towards a harmonized approach for Human Biomonitoring surveys throughout Europe. The main objective was to sustain environmental health policy by building a coherent and sustainable framework and by increasing the comparability of data across countries. A pilot study to test common guidelines for setting up surveys was considered a key step in this process. Through a bottom-up approach that included all stakeholders,
\end{abstract} a joint study protocol was elaborated.

\footnotetext{
* Correspondence to: Center for Human Genetics, University of Leuven, Herestraat 49, 3000 Leuven, Belgium.

E-mail address: Ludwine.Casteleyn@med.kuleuven.be (L. Casteleyn).
} 
Keywords:

Human Biomonitoring

Environmental health policy

European harmonization

Ethics

Study protocol
From September 2011 till February 2012, 17 European countries collected data from 1844 motherchild pairs in the frame of DEMOnstration of a study to COordinate and Perform Human Biomonitoring on a European Scale (DEMOCOPHES). ${ }^{1}$ Mercury in hair and urinary cadmium and cotinine were selected as biomarkers of exposure covered by sufficient analytical experience. Phthalate metabolites and Bisphenol $\mathrm{A}$ in urine were added to take into account increasing public and political awareness for emerging types of contaminants and to test less advanced markers/markers covered by less analytical experience. Extensive efforts towards chemo-analytical comparability were included.

The pilot study showed that common approaches can be found in a context of considerable differences with respect to experience and expertize, socio-cultural background, economic situation and national priorities. It also evidenced that comparable Human Biomonitoring results can be obtained in such context. A European network was built, exchanging information, expertize and experiences, and providing training on all aspects of a survey. A key challenge was finding the right balance between a rigid structure allowing maximal comparability and a flexible approach increasing feasibility and capacity building. Next steps in European harmonization in Human Biomonitoring surveys include the establishment of a joint process for prioritization of substances to cover and biomarkers to develop, linking biomonitoring surveys with health examination surveys and with research, and coping with the diverse implementations of EU regulations and international guidelines with respect to ethics and privacy.

(c) 2014 Elsevier Inc. All rights reserved.

\section{Introduction}

Estimates of the impact of environmental exposures on health are limited and contradictory. Part of the uncertainty lies in the high level of misclassification of exposures that hampers environmental health risk assessment (Weuve and Yonasky, 2012; Willett, 2002; Blair et al., 2009). Scientists, policy-makers and the general public have long focused mainly on external exposure assessments for regulation and control. In analogy with practices in occupational health and as technologies evolved, focus has now increasingly turned to pollution in the body, seized by the notion of body burden: the presence of chemicals in the body. Such body burdens can be assessed through Human Biomonitoring (HBM), which integrates information on exposure to potentially toxic chemical elements and substances from all sources (soil, water, air, food, packaging and consumer products) as well as bioavailability, toxicokinetics and metabolism (Angerer et al., 2007). HBM and other biomarker studies have shown their use in research, in surveys and in advocacy efforts. Whilst research projects are typically hypothesis driven and geared at the collection of data to link health outcomes causally to exposures, the objective of surveys typically is to support and evaluate public health policy by producing information on the prevalence of exposure to environmental toxicants based on periodic monitoring (European Commission, 2004; ECETOC, 2005; National Research Council of the National Academies, 2006).

HBM is a powerful tool in the democratization of knowledge of exposure. Personal exposure information in particular might have a strong impact on societal perception of environmental pollution. Human biomarkers data make pollution 'personal' and can raise awareness, support preventive actions at individual and collective level, and contribute to policy making (Stokstad, 2004). The full exploitation of the potential benefits of HBM surveys in environmental health requires accurate knowledge transfer and integration. Findings of HBM efforts however, often fail to find their way into policy and practice, resulting in a limited impact on public health policies and programs. Often single teams have proprietary control of their data and specimens; the inner workings of protocols and analyzes are invisible to outsiders and raw data do not become available (Khoury et al., 2013). HBM surveys increasingly obtain a legal embedding at national or regional level, permitting repeated cycles of measurement (Viso et al., 2009). In 2004, the European Commission started discussions on a harmonized approach throughout Europe (European Commission, 2003; European Commission, 2004; Casteleyn et al., 2007) so to improve

\footnotetext{
${ }^{1}$ http://www.eu-hbm.info/democophes (last accessed October 15 2014).
}

comparability. A European pilot study was proposed to "test the hypothesis that human biomonitoring in the field of environment and health can be performed in a coherent and harmonized approach throughout Europe by means of commonly developed protocols, strategies and scientific tools ensuring reliable and comparable data, whilst also leading to a more effective use of resources". In an interdisciplinary context, epidemiologists, chemists, toxicologists, geneticists, exposure scientists, medical professionals, social scientists and environmental health experts and policy makers, working in the fields of environmental health, public health, research and policy evaluation and support, worked closely together to develop the framework. A stakeholders group set up by the European Commission (European Commission, 2003) ${ }^{2}$ was involved in this process. Study population, exposures and outcomes, as well as parameters to be estimated, were partly defined during a broad negotiation process from 2004 until 2010. Finally a consortium of scientists from 27 European countries completed the decisions during the final negotiation process from September 2010 until March 2011 and developed a common European HBM study protocol, despite dissimilarities in approaches, technical jargon, understanding of concepts and national priorities. An extensive exchange system was set up to take into account national particularities, existing experience, expertize and infrastructure. Organizations from 17 countries, all member of the consortium, implemented the pilot study DEMOCOPHES. ${ }^{3}$ This article reports on the opportunities and the challenges for a European harmonization of HBM surveys in environmental health. It addresses the set-up of a pilot feasibility study and related discussions on data sharing, prioritization, linking with health examination, research and policy. Finally, it also discusses ethics and privacy issues as the transboundary nature of the study in a legal framework with diverse transpositions of EU regulations or of international guidelines into national laws was thought to be an additional obstacle for harmonization of methodologies and comparability of results.

\section{A common study protocol}

The common European study protocol was built in line with STrengthening the Reporting of OBservational studies in Epidemiology: Molecular Epidemiology (STROBE ME) guidelines (Gallo et al., 2011) developed to facilitate reporting of biomarker-based

\footnotetext{
${ }^{2}$ http://ec.europa.eu/health/healthy_environments/working groups/index en. htm (last accessed April 8 2014).

3 http://www.eu-hbm.info/democophes/project-partners (last accessed October 15 2014).
} 
Box 1-Table of contents of the European study protocol.

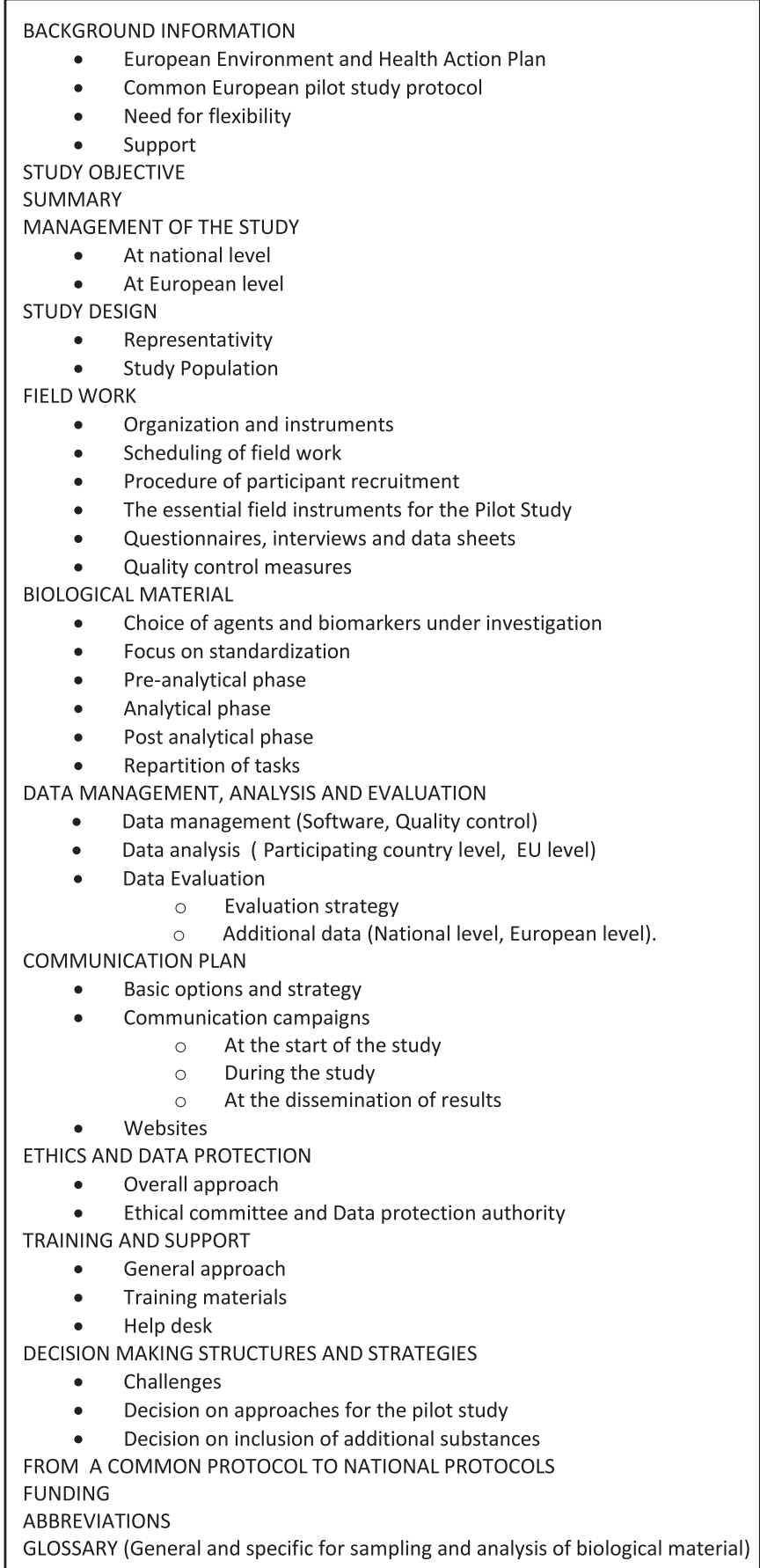

studies. Specific additions from STROBE ME to the STROBE guidelines relate to the collection, handling and storage of biological samples; laboratory methods, validity and reliability of biomarkers; specificities of study design; and ethical considerations. Finally the protocol contains detailed provisions and procedures for all stages of the study (see Box 1).

Due to the differences in registration governance, culture and ethics, a rigid scheme of mandatory operational procedures for all participating countries did not seem appropriate. Instead, the individual participating countries had the possibility to adapt certain

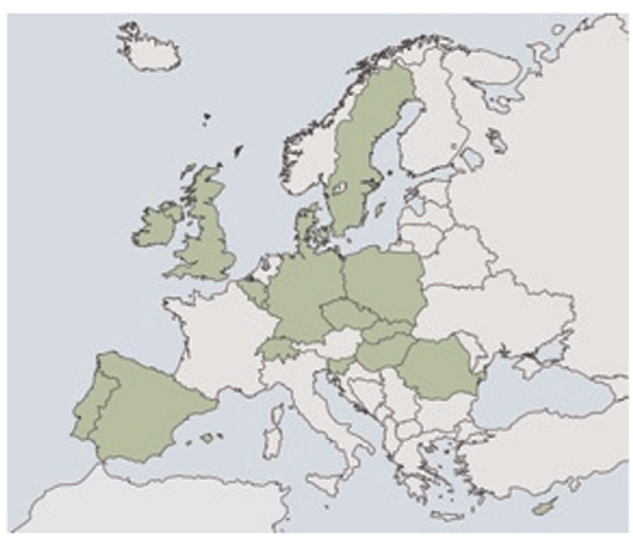

Fig. 1. Countries implementing the pilot study (in green): $\mathrm{BE}, \mathrm{CH}, \mathrm{CY}, \mathrm{CZ}, \mathrm{DE}, \mathrm{DK}$, ES, HU, IE, LU, PL, PT, RO, SE, SI, SK, UK. (For interpretation of the references to color in this figure legend, the reader is referred to the web version of this article.)

study elements in order to use existing resources and experience insofar this would not jeopardize the comparability of the results (Becker et al., 2014). Fig. 1 gives an overview of the countries that implemented the pilot study.

The European consensus protocol was the basis for the elaboration of national protocols in each participating country. Each country (i) set up a national team to implement the protocol, headed by a so-called National Focal Point (NFP), gathering the necessary expertize from own organizations and/or by hiring or subcontracting; (ii) could add specific topics to the protocol, e.g. to shed light on other topics of interest; (iii) had to adapt the background materials and questionnaires and translate them while maintaining comparability. During the period September 2011 till February 2012 this common European protocol was tested in the field to collect data from 1844 mother-child pairs in 17 countries (Fig. 1). Table 1 gives an overview of the main activities in DEMOCOPHES as well as their projected and real timing. The protocol is available at http://www.eu-hbm.info.

\subsection{Selection of study participants, recruitment and fieldwork}

Children (age group of 6-11 years) were defined as the primary target group of the study with their respective mothers aged up to 45 years. Recruitment of 240 individuals (120 children and their mothers) per participating country was anticipated, with an exception for the two smallest countries where 60 mother-child pairs were required. Recruitment and sampling was done from September 2011 until February 2012. Different approaches were tested: 4 countries recruited via the national population registries and 13 via schools. The mothers were interviewed on environment and residence, nutrition, smoking behavior, other exposure-relevant behavior, occupation and socioeconomic status (SES). Whenever possible, additional environmental and health data were linked to the biomarker and questionnaire data to improve interpretation of the results (Smolders et al., this issue). Children and their mothers were recruited from minimum two different sampling locations according to the population density using the upper and lower category (big city vs. rural) in each of the 17 countries implementing the pilot study, not including industrial sites. The study protocol provided clear (examples of) standard operating procedures (SOPs). Quality assurance methods for conducting the fieldwork included a Fieldwork Manual, active training programs for interviewing and sampling, as well as internal and external quality control measures. Data were collected using five questionnaires related to (i) recruitment, inclusion and exclusion criteria; (ii) sampling of hair; (iii) sampling of urine; (iv) non-responding and (v) information on nutritional and lifestyle behavior of mothers and children participating in the study. Further details on the study design 
Table 1

Gantt chart on the projected and real timing of the main activities in DEMOCOPHES

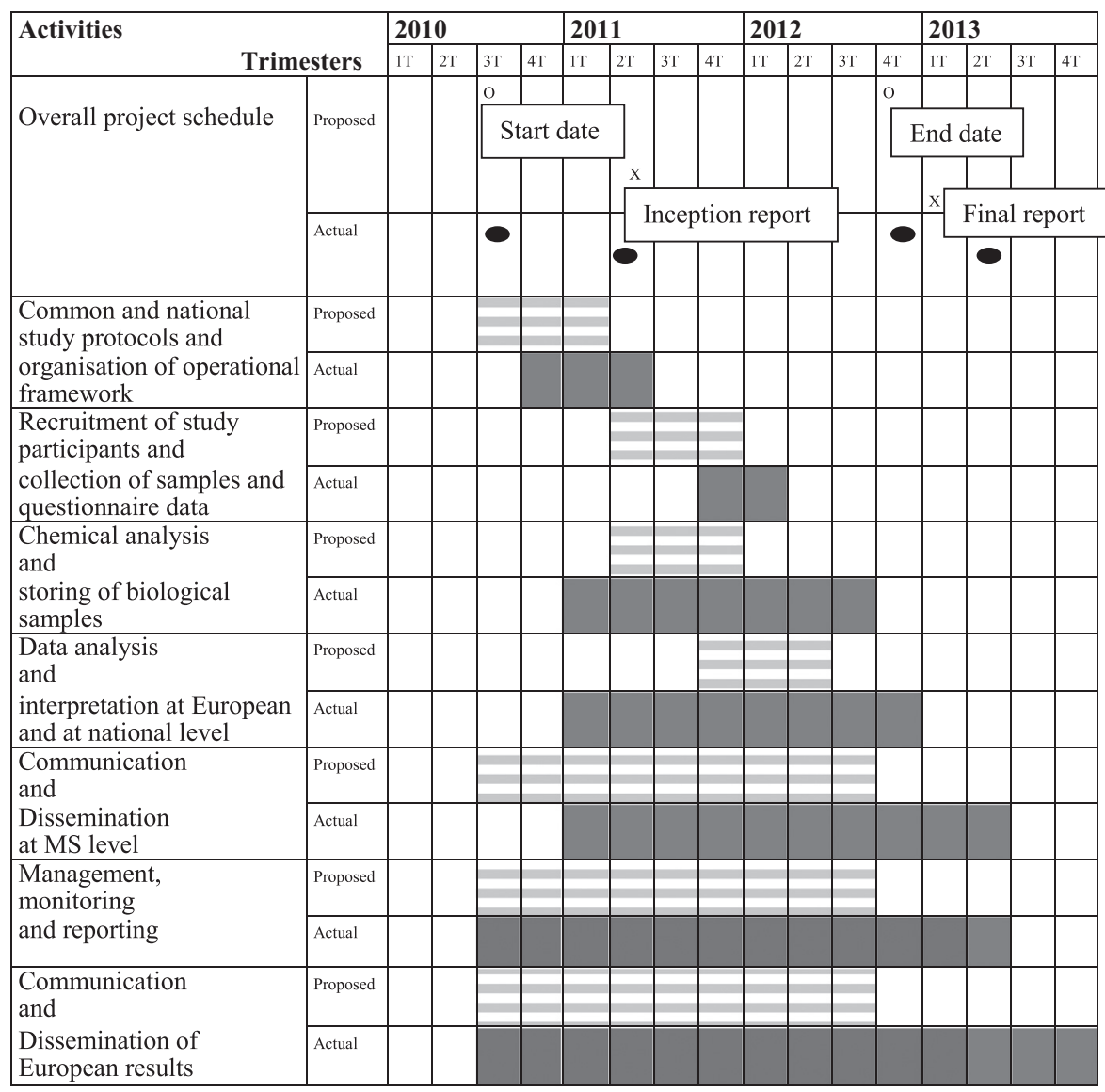

and the rationale behind it are given in Becker et al. (2014). Lessons learned on study design and fieldwork are described by Fiddicke et al., this issue.

\subsection{Biomarkers under investigation and biological sample handling}

Mercury ( $\mathrm{Hg}$ ) in hair and urinary cadmium (Cd) and cotinine were selected as biomarkers of exposure covered by sufficient analytical experience and knowledge on toxicokinetics. Phthalate metabolites in urine were included to take into account currently increasing public and political awareness for certain types of contaminants and to test inclusion of less advanced markers covered by less analytical experience. All seventeen countries measured this limited set of biomarkers. Six of these countries choose to measure urinary Bisphenol A (BPA) in addition. A common framework was established for the pre-analytical and analytical aspects. Pre-analytical SOPs included instructions and recommendations on sampling (material selection, material pretreatment) and how to collect the target biological matrices (urine and hair), besides practical aspects like packing of samples, shipment and preservation. For the analytical phase, SOPs were suggested with instructions on the analysis of the DEMOCOPHES biomarkers. A central element was the implementation of quality assurance and control strategies. For the biomarkers chosen, appropriate control/reference materials enabled the required internal quality assurance. External quality assurance was provided by several External Quality Assessment exercises: two inter-laboratory comparison investigations (ICI) and two external quality assessment schemes (EQUAS) (Schindler et al., 2014; Esteban et al., this issue). Effective capacity building was guaranteed trough web meetings discussing the results of the ICI and EQUAS programmes and at a workshop on Quality of Analytical Data in Human Biomonitoring". ${ }^{4}$ This capacity building together with the strict quality assurance and control process for the laboratories analyzing the samples, made it possible to obtain comparable biomarker measurements. Further details are described under 'Sample processing and QA' at http://www.eu-hbm.info/COPHES and http:// www.eu-hbm.info/DEMOCOPHES. The post-analytical phase includes storage of the biological samples for 10 years.

\subsection{Data management and evaluation}

A Statistical Working Group considered a number of issues with respect to databases, data analysis and interpretation. To enable the compiling of a single European database, all 17 partners implementing the pilot study had to use the same database structure. Detailed instructions were provided in a codebook and in guidelines for quality control. An automatic Quality Control (QC) process - programmed in SAS software version 9.3 (SAS Institute Inc.) - was built in order to facilitate the check of the data quality of the national databases before merging them into one European database. The R code together with a step-by-step manual and central support was provided to all NFPs. Guidelines for rounding were provided for the correct handling and processing of the biomarker values below the Limit of Quantification (LOQ). A Computer Assisted Personal Interview (CAPI) system was tested for facilitating the filling of the questionnaires. For technical

\footnotetext{
${ }^{4}$ http://www.eu-hbm.info/cophes/InformationworkshopanalyticsWP3 enviadaDIC2012.pdf (last accessed October 15 2014).
} 
reasons - the continuous Internet connection needed for using the CAPI was not always available - or for data protection reasons - the data were temporally stored on a common database abroad - many countries interviewed with the paper version and used the CAPI as a data input system only. Questionnaire data and sample measurements were processed as coded data. The European central database created with these data contains no directly identifiable personal information (e.g. address, name, etc.). Data Transfer Agreements were made between each individual partner implementing the pilot study and the central database manager. These agreements prohibit disclosure of the European pooled database in whole or in part to any third party unless agreed upon in writing by the partners providing the data. Individual partners have the right to disclose their own data to others, in accordance with the ethics and privacy rules. After the end of this agreement (in 2017) the European database manager has to destroy the data received from each country and merged in the pooled European database, unless another agreement has been made with all partners in the meantime. Approach and results of the statistical analysis are described by Den Hond et al. (2015).

\subsection{Communication strategy}

Communication was essential throughout the pilot study, not just limited to the informed consent procedure, but stretched out over the recruitment, research and follow-up phases and playing at the individual as well as the collective level. Guidelines for all communication steps, from initiation of the study to recruitment till dissemination of results, were included in the common protocol. Templates to facilitate harmonized approaches were provided. Because of ethical and democratic rules, European individuals are entitled to be informed on uses, users and results related to their samples and data (Casteleyn et al., 2010). Templates for reporting results to the individual study participants contained information on the health relevance of the data. The fact sheets also included recommendations for individual exposure reduction. Actions at community level and participatory approaches were encouraged. Process, material and results are described in more detail in this special issue (Exley et al., this issue). To inform and engage not only scientists, but also policymakers, authorities, NGO's and industry of the preliminary results and conclusions of the pilot study, they were presented at a conference held in the framework of the Presidency of the European Union (Cyprus Presidency Conference, 2012). Between October 2012 and June 2013, each of the 17 countries organized a national symposium to report on the aggregated results to the general public and to their policymakers, often with a lot of media attention. ${ }^{5}$ Topics of particular interest included relevance and use of HBM results for policies and in actions at national level, feasibility of a European harmonized program and the next steps required in line with both the European Environment and Health Action Plan 2004-2010 (European Commission, 2004) and the WHO Parma Declaration on Environment and Health, 2010 (WHO, 2010).

\subsection{Training}

All partners implementing the pilot study, some of them lacking established resources and capable staff, were assisted. Following a 'train the trainer approach', national team coordinators were trained during two workshops. Sessions were organized for fieldworkers and check lists were provided for internal quality control. The External Quality Assessment exercises mentioned above were considered as a training activity. The ICI/EQUAS rounds provided opportunities to check and improve the analytical methods and ensure the comparability of the analytical results. The web conferences, held after each

\footnotetext{
${ }^{5}$ http://www.eu-hbm.info/euresult/media-corner (last accessed May 13 2014).
}

exercise, allowed for an exchange of experiences between the participating laboratories and the organizers of the ICI/EQUAS. Two training sessions on database management, quality control of the data and statistical analysis were organized. More information on the training provided can be found at http://www.eu-hbm.info under 'Training'.

\subsection{Ethics and data protection}

Guidelines for the preparation of the ethical forms and for the notification to privacy authorities were given in annexes of the protocol. Forms to be submitted for ethical approval and notification to the national privacy authorities, although following a similar logic, differ from country to country. Therefore the practical preparation of the ethical forms and privacy notification was complemented by a system of exchange of experiences, bilateral contacts, and templates. Direct questions could be answered via the helpdesk. Details on ethics committees, privacy regulations, right to know, and secondary use is given below.

\subsection{Feasibility of a European framework and program}

A common approach for HBM was tested in 17 European countries. The main objective was to build a coherent and sustainable framework for HBM surveys in Europe and increase the comparability of data across countries. Testing of common guidelines for setting up surveys was considered a key step in this process. These guidelines, included in a common study protocol, were elaborated trough a bottom-up approach, engaging all participating countries to facilitate compliance, despite huge differences in cultural, social, economic background, experience and expertize. Financial means were restricted, and the number of samples was therefore limited. The pilot study convincingly showed that comparable HBM results could be obtained in 17 European countries all implementing the same study protocol, with little adaptations and with extensive efforts towards chemo-analytical comparability. Biomarker data and questionnaire data informed on exposure to a limited set of substances $(\mathrm{Hg}, \mathrm{Cd}$, tobacco, phthalates and in six countries BPA) and gave insights on exposure sources. For the first time, the results obtained are comparable on a European scale, which is a step towards European reference values. A European network was built, exchanging information, expertize and experiences, providing training facilities at several levels. The common approach to HBM allowed (i) testing the tools and protocols developed; (ii) generating for the first time comparable data for selected substances; and (iii) providing recommendations for further studies and programs. Key challenges in determining common approaches were finding the right balance between a rigid structure allowing maximal comparability and a flexible approach increasing feasibility and allowing capacity building.

The discussions underpinning the pilot study revealed also further challenges and opportunities for next steps. Stakeholders expressed several demands for a European HBM program. These included 'obtaining preliminary reference values of selected biomarkers from all participating Member States'; testing out linking of HBM values with environment and health indicators; and establishing protocols for the translation of HBM results into policy recommendations. ${ }^{6}$ Whilst these challenges are already tackled at national level in a few European countries as discussed below, a global European approach is not yet established and needs further phases.

${ }^{6}$ http://www.eu-humanbiomonitoring.org/doc/ig_rec3.pdf (last accessed May $132014)$. 


\section{Challenges and opportunities}

\subsection{Reference values}

One of the aims of setting up HBM surveys is to gain knowledge of the background exposure of the population under study and establish reference values. These are required by policymakers and researchers to support their work. Together with information on health based guidance values, which are totally different in scope and use, such reference values are deemed essential for interpretation and communication of results and for translation into preventive policies. Although definitions may differ among studies, reference values are often described as statistically derived values of the 95\% confidence intervals of estimated 95th population percentiles and indicate the upper margin of background exposure to a given pollutant in a given population at a given time. Recommendations on standardized biological reference values have been published by the International Organization for Standardization (ISO) and the International Federation of Clinical Chemistry (IFCC). They can be used to identify subjects with an increased level of exposure (in relation to background exposure) to a given environmental toxin. However, they do not represent health-related criteria for the evaluation of HBM data (Ewers et al., 1999). Reference values for environmental pollutants are established at national level in several countries and reported in peer reviewed publications. For instance, for Germany by the Human Biomonitoring Commission of the German Federal Environment Agency, based on representative population data collected in repetitive rounds within the GerES program (Conrad et al., 2013); for France by the 'Institut de Veille Sanitaire' based on representative population data collected by ENNS (Etude Nationale Nutrition Santé), the French Nutrition \& Health Survey ${ }^{7}$; for Flanders (northern part of Belgium) by the Flemish Center of Expertize for Environment and Health, based on representative population data collected in the Flemish Environment and Health Surveys (FLEHS I 2002-2006, FLEHS II 2007-2011) (Schoeters et al., 2011); for the Czech Republic by the Environmental Health Monitoring System (EHMS) (Cerná et al., 2007); for Slovenia by The National Chemicals Bureau of The Ministry of Health (Horvat et al., 2012; Snoj Tratnik et al., 2012), for Spain by the BIOAMBIENT.ES study implemented by the Institute of Health Carlos III (Pérez-Gómez et al.,2012), for Italy by the Program for biomonitoring the Italian population exposure PROBE implemented by the National Institute for Health, ${ }^{8}$ for Canada by the Canadian Health Measures Survey (Haines and Murray, 2012) and for the United States by the Human Biomonitoring part of NHANES, the US National Health and Nutrition Examination Survey (Calafat, 2012). In the European pilot study the number of samples was too small to be representative and the data obtained do not fulfill the scientific criteria for a "reference" base. They are to be seen as preliminary values. However, the sample size was considered to be sufficiently large to allow (minimal) statistical evaluations with 'preliminary' reference values for the groups chosen. For the further development of a common European HBM approach the current effort needs to be expanded to (i) measuring exposure to a larger number of substances and (ii) obtaining data from a suitable reference population, representative for the European population.

\footnotetext{
${ }^{7}$ Institut de Veille Sanitaire, http://www.invs.sante.fr/Dossiers-thematiques/ Maladies-chroniques-et-traumatismes/Nutrition-et-sante/Enquetes-et-etudes/ ENNS-etude-nationale-nutrition-sante (last accessed April 8 2014). 2014)

${ }^{8}$ http://www.iss.it/binary/publ/cont/11_9_web.pdf (last accessed October 15
}

\subsection{Prioritization of substances}

A broad list of chemical substances or their metabolites, from all major categories contributing to the individual's exposure, can be measured in blood, urine or other biological matrices. For a more comprehensive assessment of exposure at European level, the substances to address will have to be identified through a transparent process of prioritization. Such processes have been developed at national level in several countries, and follow basically similar lines with evaluation of needs, inclusion of participatory approaches, etc. In the French national biomonitoring program for instance, the selection of compounds for the ESTEBAN survey was based on the feasibility of Human Biomonitoring, toxicity and relevance (regulations and policy priorities). They were grouped based on chemical properties, toxicity, and analytical techniques. A modified Delphi method was used for the prioritization of substances. Criteria for scoring were health hazard, exposure levels, social perception, biomarker characteristics, interpretability of the results in terms of health risk, logistic and analytical feasibility, exposure prevention/reduction feasibility, and contributions to closing knowledge gaps (Filliol et al., 2014). In NHANES, selection criteria for chemical substances that have been used include affordability, availability of adequate analytical methods, easy sampling or availability of sample matrices, toxicological properties, suspected exposure levels, seriousness of health effects known or suspected to result from some levels of exposure and the need to assess the effectiveness of public health actions to reduce exposure to a chemical. The availability of biomonitoring methods with adequate performance and acceptable cost is a major consideration. The selection of substances is performed via the Federal Registry, enabling any person, entity or corporation to nominate a substance. Moreover, specific criteria have been developed to remove a substance from the survey. Details on the prioritization process for scoring nominated chemicals and the resulting scores are available at their website. ${ }^{9}$ In Flanders, prioritization of biomarkers for inclusion in the HBM program was based on criteria such as production volume, legal framework to regulate the chemical, expected exposure route for the general population, (highest) exposed group, vulnerable age group, expected health hazard, lowest exposure level associated with adverse health effects, estimated daily intake levels, guidance values for external/internal exposure, estimated margin of safety in relation to Lowest Observed Adverse Effect Level (LOAEL) or Tolerable Daily Intake (TDI), biological half-life in humans, risk for perinatal exposure, biological matrix needed for monitoring, sample volume needed for bioassay analysis, limit of detection of the biomarker value, costs, validation status of the biomarker and experience within the consortium (Steunpunt Milieu en Gezondheid, 2011). In Germany, three out of six chemicals to be authorized or banned from 2015 due to REACH regulations were identified as relevant chemicals by the German HBM system as GerES exposure data showed that they exceeded tolerable daily intakes in a considerable fraction of children living in Germany. In addition to chemicals identified as problematic in toxicological or exposure studies, a list of chemicals suggested as HBM candidates of high priority in view of consumer protection was established by the German Federal Scientific Agencies. This list includes chemicals used in cosmetics, contaminants in food, additional phthalates, phthalate substitutes, aromatic amines, benzothiazoles, musk fragrances, fluorinated and perfluorinated compounds, flame retardants, SVHC candidates (Substance of Very High Concern, REACH Art. 57) and corrosion inhibitors (Kolossa-Gehring et al., 2011).

\footnotetext{
${ }^{9}$ http://www.cdc.gov/exposurereport/chemical_selection.html (last accessed December 2014).
} 


\subsection{Analytical methods}

A basic requirement for deriving HBM assessment values for specific substances is the identification of a specific and analytically traceable biomarker. A primary requirement is that an analytical method exists (or can be developed) to provide reliable measurements of the biomarker in biological media. Several additional characteristics contribute to the usefulness of potential biomarkers, including stability, specificity and invasiveness of sampling. As mentioned before, besides adequate performance, acceptable cost is a major consideration in the prioritization of substances to address in a survey program. For many substances suitable biomarkers are available. For emerging substances however, methods need to be developed and for this as well prioritization is needed, through a transparent process. In this context, the German Federal Ministry for the Environment, Nature Conservation, Building and Nuclear Safety (BMUB) and the German Chemical Industry Association ( $\mathrm{VCI}$ ), currently work together. $\mathrm{VCI}$ assumes the responsibility and the funding for developing the new chemical-analytical methods; BMUB uses them to apply population-based HBM studies. Emphasis is placed on substances with either potential health relevance or to which the general population might potentially be exposed to a considerable extent. The work is supported by an advisory panel consisting of scientists from academia, industry and administration. Strategic decisions are made by a management committee including representatives from industry, the Ministry, and the Federal Environment Agency (Kolossa-Gehring and Becker, 2011). To our knowledge no similar initiatives exist in Europe for a transparent participatory process to identify further research needs in developing human biomarkers.

\subsection{Linking HBM surveys with health surveys and with research}

National and international funders increasingly demand operational linkage of HBM surveys with health examination surveys. High-quality health surveys are on-going in Europe, such as the European Health Interview Survey (EHIS), ${ }^{10}$ which enquires about background information, including SES, health status, health determinants and (use of) health services (Eurostat, 2010), and the local WHO MONICA studies, which monitor trends in cardiovascular diseases. ${ }^{11}$ In addition, the EU funded European Health Examination Survey project (EHES) was a collaboration to collect health data, comparable between countries and over time (Kuulasmaa et al., 2012). However, the health survey initiatives suffer from difficulties with sustainability and a legal basis has only been adopted for EHIS. Developing a framework for combining exposure and health assessment in an integrated survey at European level using harmonized and quality controlled protocols is one of the future challenges. Several integrated approaches are already running in Europe and elsewhere. The USA's NHANES assesses the health and nutritional status of adults and children in the United States and also gathers a wealth of data, representative of the entire population's exposure to pollutants. The Canadian Health Measures Survey (CHMS) collects information from Canadians about their general health and includes measurements of chemicals in blood and urine samples. In Europe, Germany (Schulz et al., 2007), the Czech Republic (Cerná et al., 2012) and Slovenia (Horvat et al., 2012) perform health examination surveys combined with

\footnotetext{
${ }^{10}$ http://epp.eurostat.ec.europa.eu/portal/page/portal/product_details/publica tion?p_product_code=KS-RA-13-018 (last accessed May 14 2014).

11 http://www.thl.fi/monica/ (last accessed April 11 2014).
}

HBM. Recently also France placed special emphasis on the use of an integrated (HBM coupled with nutrition and health studies) multi-pollutant approach. This approach has been initiated in France with a national population-based biomonitoring survey, the 'Etude nationale nutrition santé' (ENNS; French national survey on nutrition and health). This survey provided the first reference distribution for 42 biomarkers in the French population. The current national HBM strategy builds upon the ENNS and includes a national survey of people aged between 6 and 74 years complemented for the neonatal period and childhood by the 'Etude Longitudinale Française depuis l'Enfance' (ELFE; French longitudinal study of children) (Fréry et al., 2012).

Many biomarkers of exposure used in HBM programs address single chemicals one at a time and are limited in respect to validation and integration with health outcomes. Much research is needed for improved understanding of environment-health-disease associations and their underlying mechanisms. More recently developed biomarkers (i.e. omics-derived biomarkers) offer great promise in refining exposure estimates and establishing biological plausibility of exposure-disease associations. These markers represent a continuum of cellular responses to drug or chemical exposures and provide linkages to mechanisms of cell injury/cell death or carcinogenic transformation. Recent EU-funded projects such as Human Early-Life Exposome (HELIX) ${ }^{12}$; EXPOsOMICS ${ }^{13}$; Health and Environment-wide Associations based on Large population Surveys (HEALS) ${ }^{14}$ and Cross-Mediterranean Environment and Health Network (CROME) ${ }^{15}$ attempt to link collected exposure data to biochemical and molecular changes in our body so to improve our understanding on how these pollutants influence the risk of developing chronic diseases. They apply the exposome concept, a novel approach to studying the role of the environment in human disease, which refers to the totality of environmental exposures from conception onwards. However, application for risk assessment in public health is still limited due to implementation, validation and interpretation issues (Wild, 2005; Smith et al., 2005; Vineis et al., 2011; Rappaport, 2012; Wild, 2011). The combination of traditional methods for assessment of individual exposure through cross sectional surveys with these omics techniques might be an opportunity to forward the development of preventive strategies. Data on chemical exposures that have not been hypothesized a priori as having an impact on health may be generated and patterns or individual profiles that go beyond single chemical approaches may be identified. Follow up studies in which the individual health and disease status is further monitored should allow identifying biomarkers and individual molecular profiles that are predictive of disease risk. The hypotheses thus generated, have to be further investigated in nested case-control studies in existing longitudinal cohorts (Vineis and Perera, 2007).

\subsection{Knowledge transfer and integration}

Environmental health is a sensitive issue in society. Both at collective and at individual level information on exposure and burden of disease is required. The public at large and policymakers want to evaluate related policies such as the Regulation on classification, labeling and packaging of substances and mixtures, ${ }^{16}$ the Regulation (EC 1907/2006) on the Registration Evaluation and

\footnotetext{
12 http://www.projecthelix.eu/ (last accessed October 15 2014).

13 http://www.exposomicsproject.eu/mission (last accessed October 15 2014).

14 http://www.heals-eu.eu (last accessed October 15 2014).

15 http://www.crome-life.eu/ (last accessed October 15 2014).

16 http://ec.europa.eu/enterprise/sectors/chemicals/classification/index_en. htm (last accessed May 13 2014).
} 
Authorization of Chemicals ${ }^{17}$, the Strategic Approach to International Chemicals Management (SAICM), ${ }^{18}$ the OECD Cooperative Chemicals Assessment Program, ${ }^{19}$ the Stockholm Convention on POPs, ${ }^{20}$ the Regulation (EC 1107/2009) on the placing of plant protection products on the market, ${ }^{21}$ the Regulation (EU 528/2012) on biocidal products, ${ }^{22}$ the EU Cosmetics Directive (EU, 1976), and the EU Directive on chemical agents at work (EU, 1998). Also, European regulatory agencies and committees involved in risk assessment need more information on European exposure. The agencies and committees involved are the European Food Safety Agency, ${ }^{23}$ the European Environment Agency, ${ }^{24}$ the European Medicines Agency ${ }^{25}$ and the European Chemicals Agency ${ }^{26}$ as well as the independent Scientific Committees advising on proposals relating to consumer safety, public health and the environment. ${ }^{27}$ However, access to data is not always straightforward: traditionally single research teams have proprietary control of their data and specimens. Protocols, analyzes and raw data are often not directly available. The European approach anticipated a maximal potential broad availability of data, protocols and analyzes from the pilot study despite legal, ethical or pragmatic reasons that may hinder full transparency. Information at layman's level was provided in 15 languages at the nationa ${ }^{28}$ and European ${ }^{29}$ websites of the pilot study.

In the EU Environment and Health Strategy, special consideration was asked for an accurate translation to policy. Data generated should bear relevant and useful information for risk managers and policymakers in terms of developing, adapting and evaluating environmental policies (Smolders et al., 2008). Despite its nature of pilot study with obvious limitations in substances and population covered, data from the DEMOCOPHES pilot study so far assisted with research on the economic calculation of the cost of the actual exposure of Europeans to mercury, which supported the UNEP discussions on measures to reduce exposure to this widespread heavy metal (Bellanger et al., 2013). The methodology tested also supported the important efforts by WHO for a harmonized generation of HBM data in the WHO European region, with a broader coverage of 53 countries. The Parma Declaration on Environment and Health, adopted at the 5th Ministerial Conference on Environment and Health in 2010, calls for the intensification of actions by the Member States of the WHO European Region to protect children's health from environmental hazards, such as harmful chemicals including carcinogens, mutagens, reproductive toxicants and endocrine disruptors. The Parma Declaration specifically recognized pregnant and breast-feeding women as target population groups for actions aimed at identifying and reducing environmental risks as far as possible by 2015 . The Member States also committed themselves to developing a

\footnotetext{
17 http://ec.europa.eu/enterprise/sectors/chemicals/reach/index_en.htm (last accessed May 13 2014)

${ }^{18}$ http://www.saicm.org/ (last accessed May 13 2014).

19 http://www.oecd.org/chemicalsafety/risk-assessment/oecdcooper

ativechemicalsassessmentprogramme.htm (last accessed May 13 2014).

$20 \mathrm{http}: / / \mathrm{chm}$.pops.int/Implementation/GlobalMonitoringPlan/MonitoringActiv ities/tabid/181/Default.aspx (last accessed May 13 2014).

21 http://europa.eu/legislation_summaries/food_safety/plant_health_checks/ sa0016_en.htm (last accessed May 13 2014).

22 http://echa.europa.eu/regulations/biocidal-products-regulation (last accessed May 13 2014).

${ }^{23}$ http://www.efsa.europa.eu/ (last accessed May 13 2014).

24 http://www.eea.europa.eu/ (last accessed May 13 2014).

25 http://www.ema.europa.eu/ema/ (last accessed May 13 2014).

26 http://echa.europa.eu/regulations/biocidal-products-regulation (last accessed May 13 2014).

27 http://ec.europa.eu/health/scientific_committees/about/index_en.htm\%20 (last accessed May 13 2014).

${ }^{28}$ http://www.eu-hbm.info/democophes/project-partners (last accessed May 13 2014).

${ }^{29}$ http://www.eu-hbm.info/democophes (last accessed May 13 2014).
}

consistent and rational approach to Human Biomonitoring (HBM) as a complementary tool for evidence-based public and environmental health measures. In order to enable efficient monitoring of the progress towards these time-bound goals, the WHO European Center for Environment and Health (ECEH) has been coordinating the development of biomonitoring-based indicators. Early life exposure to mercury and polybrominated diphenyl ethers (PBDEs) were identified as the most relevant biomonitoring-based indicators of exposure supplementing the HBM-based indicators blood lead level in children and dioxins in human milk, which have already been implemented in WHO's European Environment and Health Information System (ENHIS) (WHO, 2010; Egorov, 2012).

It is increasingly acknowledged that communication in HBM needs specific skills and support of appropriate expertize to address the questions of what is to be communicated, to whom, under which form, and at what time (Casteleyn et al., 2010). Particular challenges are for example in transferring messages with a scientific and technical content to an audience with no background in science and to explain the uncertainties. In addition, participatory approaches are becoming incorporated in HBM surveys (Morello-Frosch et al., 2009, 2014). The answers to these challenges might influence the success of future survey programs. Good communication will increase trust and confidentiality in research and impact participatory rates (Halkoaho et al., 2012).

\section{Ethics and privacy: an obstacle?}

The donation of tissues or fluids by healthy volunteers implies sensitive ethical and privacy questions. To ensure the protection of the rights and dignity of study participants a complex legal and ethical framework exists in Europe. One of the most important international references to define and safeguard fundamental human rights in the field of biomedical research, in particular of those participating in research, is the Oviedo Convention ${ }^{30}$ and its Additional Protocol concerning Biomedical Research. ${ }^{31}$ They set out the fundamental principles applicable in day-to-day medicine as well as those applicable to new technologies in human biology and medicine. The Oviedo Convention is an international convention. Its action extends to all countries that have ratified it. The Oviedo Convention has currently been signed by 34 Member States of the Council of Europe, of which 21 have so far also ratified the Convention. ${ }^{32}$ Ten of the 17 countries of the pilot study have ratified the Oviedo Convention. The European Court of Human Rights uses the Oviedo Convention as an expression of European human rights standards, even in cases involving countries that have not signed or ratified the convention. The Additional Protocol on biomedical research entered into force after five ratifications on $01 / 09 / 2007$. Of particular relevance for the pilot study was the question whether the diverse implementations of EU regulations or of international guidelines into domestic law would hinder the harmonization of methodologies and the comparability of results.

\subsection{Ethics committees}

The Additional Protocol emphasizes the necessity of obtaining informed consent and requires that a research project is submitted to an ethics committee for independent examination of its

\footnotetext{
${ }^{30}$ http://conventions.coe.int/Treaty/en/Treaties/Html/164.htm (last accessed May 13 2014).

31 http://conventions.coe.int/Treaty/en/Treaties/Html/195.htm (last accessed May 13 2014).

32 http://conventions.coe.int/Treaty/Commun/ChercheSig.asp? $\mathrm{NT}=164 \& \mathrm{CM}=\& \mathrm{DF}=\& \mathrm{CL}=\mathrm{ENG}$ (last accessed May 132014 ).
} 
scientific merit and multidisciplinary review of its ethical acceptability. All countries participating in the pilot study needed approval from an ethics committee. The time needed to obtain approval varied strongly between countries and situated in the range from 0 - in one country the study proposal was submitted and clarified to the ethics committee at their meeting and approval was obtained the same day - to 113 days. Table 2 gives an overview of the time needed.

Most frequently requested documents are a summary of the protocol (in English), the informed consent form (in local language) and all documents related to communication to the participants (in local language). In four countries the curriculum vitae of the investigators were requested. One ethics committee also required a statement of no conflict of interest of the collaborators. In one country a General Practitioner (GP) booklet was required advising GPs on the study and providing information on the follow-up management of participants, including whether repeat testing of the chemicals under study was required. In this case, all GPs in the local area where the sampling occurred were sent a brochure. Also an external auditor (Medical Doctor) to whom participants could communicate any complains or worries had to be appointed. In two countries the ethics committee stressed that those who respond that they do not want to participate cannot be pressed into completing a non-responder questionnaire. Table 3 gives an overview of the documents submitted in English and/or translated into local language.

\subsection{Data protection}

The Data Protection Directive 95/46/EC regulates the processing of personal data within the EU. ${ }^{33}$ It places obligations on organizations using personal information and gives individuals certain rights. Samples and data obtained in a Human Biomonitoring study are considered sensitive personal data related to health Processing of such data is in principle forbidden, unless certain conditions are met. Scientific research and government statistics are stated to be "of important public interest" and are facilitated. In the pilot study, samples and data were coded for processing. The directive states that those who record and use personal data must be open about how the information is used and must follow the principles of 'good information handling' laid down in the Directive. The Data Protection Directive imposes the practice of informed consent, including the right to know one's own individual results, and notification of the research to the national data protection supervisory authority. Although the Data Protection Directive is implemented in all EU member states, significant differences in practices exist between countries. Six countries declared that notification was not required, because data protection issues are included in the applications to the ethics committees. Four countries needed to give additional clarification. Differences in time frame are also remarkable: the time for receiving an answer differed from 0 - when no notification was needed or no answer was foreseen - to 182 days. Table 2 gives an overview for the 17 countries.

\subsection{Right to know, right not to know}

The National Academy of Science Report Human Biomonitoring for Environmental Chemicals (NAS, 2008) supported the right to know: “... it is better for the individual to possess this (body burden) information than not...subjects should be told (or offered the chance to be told) whatever researchers know (or do not know)...". In

${ }^{33}$ http://eur-lex.europa.eu/LexUriServ/LexUriServ.do?uri=CELEX:31995L0046: en:HTML (last accessed May 14 2014).
Table 2

Time for approval by ethics committees and for replies by privacy authorities.

\begin{tabular}{lll}
\hline Country & No of days approval ethics & No of days notification privacy \\
\hline 1 & 0 & 0 \\
2 & 9 & 168 \\
3 & 13 & 0 \\
4 & 23 & 0 \\
5 & 28 & $* *+0$ \\
6 & 28 & 0 \\
7 & 36 & 75 \\
8 & 43 & 134 \\
9 & 43 & 26 \\
10 & 56 & 0 \\
11 & 70 & 0 \\
12 & 77 & 0 \\
13 & 81 & 56 \\
14 & 92 & 0 \\
15 & 94 & 0 \\
16 & 99 & 37 \\
17 & 113 & 182 \\
\hline
\end{tabular}

Approval Ethics: 0 days means that approval was received the day of formal submission.

Notification Privacy: 0 days means that data protection issues were included in the application to the ethics committee or that no answer from the privacy authorities was required.

All of the actions took place between December 2010 and February 2012.

* Approval under conditions; final approval 112 days later.

** General notification was included in the application to the ethics committee, but to obtain address data from the inhabitants register a notification had to be sent to each municipality were subjects were recruited since data protection was managed at municipal level.

Europe the right to know and not to know for an individual is stated both in the EU Directive on Data Protection (art. 12) and in the Additional Protocol to the Oviedo Convention regarding Biomedicine (art. 10). The Data Protection Directive does not mention any exceptions on the right (not) to know. Article 26.1 of the Convention however states that in exceptional circumstances, restrictions may be placed against the right not to know: exceptions can be prescribed by law and are necessary in a democratic society in the interest of public safety, for the prevention of crime, for the protection of public health or for the protection of the rights and freedoms of others. The right not to know of the person concerned may thus be opposed to the interest to be informed of another person or of the public at large and these interests should be balanced by internal law. It may also be of vital importance for an individual to know certain facts about his/her health. But, here too it will be for domestic law to indicate whether the doctor, in the light of the circumstances of the particular case, may make an exception to the right not to know. Domestic law may justify the doctor sometimes disclosing information with circumspection ("therapeutic necessity"). In the pilot study, the informed consent forms used allowed the study subjects to indicate their wish to know or not to know the results. The ethics committee of one country was very clear on the statement of overriding the right not to know in cases of very high concentrations of toxicants. It had to be included in the informed consent form that if concentration of toxicants were abnormally high, this person should be re-contacted for results. In another country, the ethical committee objected to dissemination of the individual results to all participants and allowed only to disseminate to individual participants with exceptionally high values, with advice to contact their doctor.

\subsection{Secondary use}

Under the current regulations, the issue of reusing data can be a very complex one to tackle, in terms of effort, time and costs, especially if identifiable data is to be used. Nevertheless, a strong call exists for more re-use of data (Miller, 2009). In the pilot study 
Table 3

Overview of documents submitted to ethics committees.

\begin{tabular}{|c|c|c|c|c|c|c|c|c|c|c|c|c|c|c|c|c|c|c|c|c|c|c|c|c|c|c|c|c|c|c|}
\hline Country & 1 & & 2 & & 3 & & 4 & & 5 & & 6 & 7 & & 8 & & 9 & 10 & & 11 & & 12 & 13 & & 14 & 15 & & 16 & & 17 & \\
\hline Document/ English (E) Translated (T) & $\mathbf{E}$ & $\mathbf{T}$ & $\mathbf{E}$ & $\mathbf{T}$ & $\mathbf{E}$ & $\mathbf{T}$ & $\mathbf{E}$ & $\mathbf{T}$ & $\mathbf{E}$ & $\mathbf{T}$ & E $\mathbf{T}$ & $\mathbf{T} \mathbf{E}$ & $\mathbf{T}$ & $\mathbf{E}$ & $\mathbf{T}$ & $\mathbf{E} \mathbf{T}$ & $\mathbf{E}$ & $\mathbf{T}$ & $\mathbf{E}$ & $\mathbf{T}$ & E $\mathbf{T}$ & $\mathbf{E}$ & $\mathbf{T}$ & E $\mathbf{T}$ & $\mathbf{E}$ & $\mathbf{T}$ & $\mathbf{E}$ & $\mathbf{T}$ & $\mathbf{E}$ & $\mathbf{T}$ \\
\hline 1. Submission letter & & $\mathrm{X}$ & & & $\mathrm{x}$ & $\mathrm{X}$ & $\mathrm{X}$ & & & $\mathrm{X}$ & $\mathrm{x}$ & & $\mathrm{X}$ & & $\mathrm{x}$ & $\mathrm{X}$ & & & & $\mathrm{X}$ & $\mathrm{X}$ & & $\mathrm{X}$ & & $\mathrm{X}$ & $\mathrm{X}$ & $\mathrm{x}$ & $\mathrm{x}$ & & $\mathrm{X}$ \\
\hline 2. Specific application form & & $\mathrm{X}$ & & & $\mathrm{X}$ & & $\mathrm{X}$ & & & $\mathrm{X}$ & & & $\mathrm{X}$ & & $\mathrm{X}$ & $\mathrm{X}$ & & $\mathrm{X}$ & & $\mathrm{X}$ & $\mathrm{X}$ & & $\mathrm{x}$ & $\mathrm{X}$ & $\mathrm{X}$ & & $\mathrm{x}$ & $\mathrm{x}$ & & $\mathrm{X}$ \\
\hline 3. Summary of the project & & $\mathrm{X}$ & & $\mathrm{X}$ & $\mathrm{X}$ & & $\mathrm{X}$ & $\mathrm{X}$ & & $\mathrm{X}$ & $x$ & $\mathrm{X}$ & $\mathrm{X}$ & & $\mathrm{X}$ & $\mathrm{X}$ & $\mathrm{X}$ & $\mathrm{X}$ & & $\mathrm{X}$ & $\mathrm{X}$ & & $\mathrm{X}$ & $\mathrm{X}$ & $\mathrm{X}$ & $\mathrm{X}$ & $\mathrm{X}$ & $\mathrm{x}$ & & $\mathrm{X}$ \\
\hline 4. EU protocol & $\mathrm{X}$ & $\mathrm{X}$ & & & $\mathrm{X}$ & & $\mathrm{X}$ & & $\mathrm{X}$ & & $\mathrm{X}$ & & & & & $\mathrm{X}$ & $\mathrm{X}$ & & $\mathrm{X}$ & & $\mathrm{X}$ & & $\mathrm{X}$ & $\mathrm{X}$ & $\mathrm{X}$ & $\mathrm{X}$ & $\mathrm{X}$ & & $\mathrm{X}$ & \\
\hline 5. Addition to the protocol & & $\mathrm{X}$ & & & $\mathrm{X}$ & & $\mathrm{X}$ & & & $\mathrm{X}$ & $\mathrm{X}$ & & & & $\mathrm{X}$ & & & & $\mathrm{X}$ & & $\mathrm{X}$ & & $\mathrm{X}$ & & & & & & & $\mathrm{X}$ \\
\hline 6. Policy fact sheet & $\mathrm{X}$ & & & $\mathrm{X}$ & $\mathrm{X}$ & $\mathrm{X}$ & & & & $\mathrm{X}$ & & $\mathrm{X}$ & & & & $\mathrm{X}$ & & & & & & & $\mathrm{X}$ & & & & & & & \\
\hline 7. Invitation ( $1 \mathrm{st}$ ) letter & $\mathrm{X}$ & & & $\mathrm{X}$ & $\mathrm{X}$ & $\mathrm{X}$ & $\mathrm{X}$ & $\mathrm{X}$ & & $\mathrm{X}$ & & $\mathrm{X}$ & $\mathrm{X}$ & & $\mathrm{X}$ & $\mathrm{X}$ & & $\mathrm{X}$ & $\mathrm{X}$ & $\mathrm{X}$ & $\mathrm{X}$ & & $\mathrm{X}$ & $\mathrm{X}$ & $\mathrm{X}$ & $\mathrm{X}$ & $\mathrm{X}$ & $\mathrm{x}$ & & \\
\hline 8. Information leaflet & $\mathrm{X}$ & & & & $\mathrm{X}$ & $\mathrm{X}$ & $\mathrm{X}$ & $\mathrm{X}$ & & $\mathrm{X}$ & & $\mathrm{X}$ & $\mathrm{X}$ & & $\mathrm{X}$ & $\mathrm{X}$ & & $\mathrm{X}$ & $\mathrm{X}$ & & $\mathrm{X}$ & & $\mathrm{x}$ & $\mathrm{X}$ & $\mathrm{X}$ & $\mathrm{X}$ & $\mathrm{X}$ & $\mathrm{x}$ & & \\
\hline 9. Information leaflet for children & & & & & $\mathrm{X}$ & $\mathrm{X}$ & & & & $\mathrm{X}$ & & & $\mathrm{X}$ & & & $\mathrm{X}$ & & $\mathrm{X}$ & $\mathrm{X}$ & & $\mathrm{X}$ & & & & $\mathrm{X}$ & $\mathrm{X}$ & & & & \\
\hline 10. Reply card & & & & & $\mathrm{X}$ & $\mathrm{X}$ & & & & $\mathrm{X}$ & & $\mathrm{X}$ & & & $\mathrm{X}$ & $\mathrm{X}$ & & & & & $\mathrm{X}$ & & & & $\mathrm{X}$ & $\mathrm{X}$ & $\mathrm{x}$ & $\mathrm{x}$ & & \\
\hline 11. Reminder letter & & & & & $\mathrm{X}$ & $\mathrm{X}$ & & & & $\mathrm{X}$ & & $\mathrm{X}$ & & & $\mathrm{X}$ & $\mathrm{X}$ & & & & & & & & & & & $\mathrm{X}$ & $\mathrm{X}$ & & \\
\hline 12. Appointment (2nd) letter & & & & & $\mathrm{X}$ & $\mathrm{X}$ & & & & $\mathrm{X}$ & & $\mathrm{X}$ & & & & $\mathrm{X}$ & & & & & & & & & & & $\mathrm{X}$ & $\mathrm{X}$ & & \\
\hline 13. Informed Consent form & & $\mathrm{X}$ & & $\mathrm{X}$ & $\mathrm{X}$ & $\mathrm{X}$ & $\mathrm{X}$ & $\mathrm{X}$ & & $\mathrm{X}$ & & $\mathrm{X}$ & $\mathrm{X}$ & & $\mathrm{X}$ & $\mathrm{X}$ & & $\mathrm{X}$ & $\mathrm{X}$ & $\mathrm{X}$ & $\mathrm{X}$ & & $\mathrm{X}$ & & $\mathrm{X}$ & $\mathrm{X}$ & $\mathrm{X}$ & $\mathrm{x}$ & & $\mathrm{X}$ \\
\hline 14. Informed Assent for children & & & & & $\mathrm{X}$ & $\mathrm{X}$ & & & & $\mathrm{X}$ & & & & & $\mathrm{X}$ & $\mathrm{X}$ & & & $\mathrm{X}$ & & $\mathrm{X}$ & & & & $\mathrm{X}$ & $\mathrm{X}$ & & & & $\mathrm{X}$ \\
\hline 15. Withdrawal letter & & $\mathrm{X}$ & & & $\mathrm{X}$ & $\mathrm{X}$ & & & & $\mathrm{X}$ & & $\mathrm{X}$ & & & $\mathrm{X}$ & $\mathrm{X}$ & & & & & $\mathrm{X}$ & & & & & & $\mathrm{X}$ & $\mathrm{x}$ & & $\mathrm{X}$ \\
\hline 16. Letter of thanks & & & & & $\mathrm{X}$ & $\mathrm{X}$ & & & & $\mathrm{X}$ & & $\mathrm{X}$ & & & $\mathrm{X}$ & $\mathrm{X}$ & & & & & & & $\mathrm{X}$ & & & & $\mathrm{X}$ & $\mathrm{x}$ & & \\
\hline 17. Pre-visit (3rd) letter & & & & & $\mathrm{X}$ & & & & & $\mathrm{X}$ & & & & & $\mathrm{X}$ & $\mathrm{X}$ & & & & & & & & & & & $\mathrm{X}$ & $\mathrm{X}$ & & \\
\hline 18. Instruction leaflet on how to provide the urine samples & & & & & $\mathrm{X}$ & & & & & $\mathrm{X}$ & & & & & $\mathrm{X}$ & $\mathrm{X}$ & & & & & & & $\mathrm{X}$ & & & & & & & \\
\hline 19. Chemical fact sheets & $\mathrm{X}$ & & & $\mathrm{X}$ & $\mathrm{X}$ & & & & & $\mathrm{X}$ & & $\mathrm{X}$ & & & $\mathrm{X}$ & $\mathrm{X}$ & & & & $\mathrm{X}$ & & & $\mathrm{X}$ & & & & $\mathrm{X}$ & $\mathrm{x}$ & & \\
\hline 20. Letter informing on the results & $\mathrm{X}$ & & & & $\mathrm{X}$ & & & & & $\mathrm{X}$ & & $\mathrm{X}$ & & & $\mathrm{X}$ & $\mathrm{X}$ & & & & $\mathrm{X}$ & $\mathrm{X}$ & & $\mathrm{X}$ & & & & $\mathrm{X}$ & $\mathrm{X}$ & $\mathrm{X}$ & \\
\hline 21. Procedure for informing on high results & & & & & $\mathrm{X}$ & & & & & $\mathrm{X}$ & & & & & & & & & & & $\mathrm{X}$ & & & $\mathrm{X}$ & & & & & & \\
\hline 22. Basic questionnaire & & & & $\mathrm{X}$ & $\mathrm{X}$ & $\mathrm{X}$ & $\mathrm{X}$ & $\mathrm{X}$ & & $\mathrm{X}$ & & $\mathrm{X}$ & $\mathrm{X}$ & & $\mathrm{X}$ & $\mathrm{X}$ & & $\mathrm{X}$ & & $\mathrm{X}$ & $\mathrm{X}$ & & $\mathrm{X}$ & & $\mathrm{X}$ & $\mathrm{X}$ & $\mathrm{X}$ & & & $\mathrm{X}$ \\
\hline 23. Hair and urine questionnaires & & & & & $\mathrm{X}$ & & & & & $\mathrm{X}$ & & $\mathrm{X}$ & $\mathrm{X}$ & & $\mathrm{X}$ & $\mathrm{X}$ & & $\mathrm{X}$ & & $\mathrm{X}$ & & & $\mathrm{X}$ & & & & $\mathrm{X}$ & & & $\mathrm{X}$ \\
\hline 24. Recruitment interview & & & & & $\mathrm{X}$ & & & & & $\mathrm{X}$ & & $\mathrm{X}$ & $\mathrm{X}$ & & $\mathrm{X}$ & $\mathrm{X}$ & & $\mathrm{X}$ & & $\mathrm{X}$ & & & & & $\mathrm{X}$ & $\mathrm{X}$ & $\mathrm{X}$ & & & $\mathrm{X}$ \\
\hline 25. Non responder questionnaire & & & & $\mathrm{X}$ & $\mathrm{X}$ & $\mathrm{X}$ & & & & $\mathrm{X}$ & & $\mathrm{X}$ & & & $\mathrm{X}$ & $\mathrm{X}$ & & $\mathrm{X}$ & & $\mathrm{X}$ & & & & & $\mathrm{X}$ & $\mathrm{X}$ & $\mathrm{X}$ & & & $\mathrm{X}$ \\
\hline 26. Attestation of insurance & & & & & & & & & & $\mathrm{X}$ & $\mathrm{X}$ & & & & & $\mathrm{X}$ & & & & $\mathrm{X}$ & $\mathrm{X}$ & & & & & & & & & \\
\hline 27. Other & & & & $\mathrm{X}$ & & & $\mathrm{X}$ & $\mathrm{X}$ & $\mathrm{X}$ & & & & $\mathrm{X}$ & $\mathrm{x}$ & $\mathrm{X}$ & & $\mathrm{X}$ & $\mathrm{X}$ & & & $\mathrm{X}$ & & $\mathrm{X}$ & & $\mathrm{X}$ & $\mathrm{X}$ & $\mathrm{X}$ & $\mathrm{x}$ & & $\mathrm{X}$ \\
\hline
\end{tabular}

the foreseen procedure for further use of the database implies that the Principal Investigator (PI) in each country has to check whether the planned analyzes and the foreseen users of the data are in line with the information as provided in the informed consent procedure, in the submission to the ethical committee and in the notification to the privacy authorities. If this is the case, the full or partial database can be transferred. If this is not the case, the PI has to re-contact the study subjects, the ethical committees and the privacy authorities. Exceptions to this rule exist if re-contacting the study subject proves impossible or would involve a disproportionate effort, or if recording or disclosure is expressly laid down by law. In these cases national laws foresee appropriate safeguards, which differ from country to country.

\subsection{Lessons learned}

In conclusion, the pilot study was performed on a pan-European scale and had to comply with dissimilar national regulations and protocols. These regulations and protocols all aim to adequately and equally protect study participants while safeguarding the possibility for environmental health-related studies to progress and obtain optimal and harmonized results. Whilst it is clear that difficulties, ambiguities or even inconsistencies exist in the way ethical and juridical challenges are framed and being dealt with, this did not cause substantial problems. The main points of attention were to foresee a timely submission of all information so as not to delay the start of the study and, in a further stage, to apply correct procedures for appropriate and efficient further uses of the database.

\section{Conclusion}

Overall the pilot study allowed (i) the development of a common study protocol, that was translated, with minor adaptations to national situations, in 17 European countries and (ii) the generation of comparable HBM data. Through a process of extensive communication and a tailor made QC system, a balance was found between flexibility and capacity building on the one hand and a rigid structure with strict criteria on the other hand. Although a limited number of biomarkers were measured and the study population did not meet the requirements for representativeness, the approach allowed not only the testing of harmonized procedures, but also to provide so-called preliminary reference values. The results supplement those of existing studies carried out or being carried out in several countries according to different protocols at regional, national or transnational level and are already used for supporting and evaluating policy. Further harmonization of practices in Europe and continuous exchange of capacities and experiences are key elements to increase the use of HBM for preventive policies and optimize the investments made. Additional efforts are necessary to develop reliable biomarkers and analytical methods and for structuring a long-term European program. To pave the way forward despite cultural, social, legal and ethical differences, the EU needs a structure that will allow for suitable coordination and organization and a transparent decisionmaking strategy in respect to choices to be made for the future implementation of HBM. Reference values at European level would give an overall view of the situation and might be the basis for actions and policies envisaging higher environmental equity across the EU. They can determine whether a person or group has an unusually high exposure and identify population groups that merit further assessment of exposure sources or health effects. Linking with health surveys would provide considerable cost savings and create new opportunities for research and policy assessment. In an environment of funding limitations and rapid technology advances, it is of utmost importance that data, biological samples, and other research resources are used in the most efficient way. Enhancing transparency, multidisciplinary collaboration, strategic applications of new technologies and transnational research are important on the way forward. 


\section{Financial support}

COPHES (COnsortium to Perform Human Biomonitoring on a European Scale) was funded by the Seventh EU Framework Programme 2007-2011 under grant agreement no [244237].

DEMOCOPHES (DEMOnstration of a study to COordinate and Perform Human Biomonitoring on a European Scale) was co-funded (50\%:50\%) by the European Commission LIFE + Programme (LIFE09/ENV/BE/000410) and the partners.

For information on both projects as well as on the national cofunding institutions: see http://www.eu-hbm.info/.

\section{Acknowledgements}

Many people contributed to the success of this project. We would in particular like to thank the mothers and children that participated in the study, the people involved in the fieldwork and laboratory work, and all our partners in COPHES and DEMOCOPHES.

\section{References}

Angerer, J., Ewers, U., Wilhelm, M., 2007. Human biomonitoring: state of the art. Int J. Hyg. Environ. Health 210 (3-4), 201-228. http://dx.doi.org/10.1016/j. ijheh.2007.01.024.

Becker, K., Seiwert, M., Casteleyn, L., Joas, R., Joas, A., Biot, P., Aerts, D., Castaño, A., Esteban, M., Angerer, J., Koch, H.M., Schoeters, G., Den Hond, E., Sepai, O., Exley, K., Knudsen, L.E., Horvat, M., Bloemen, L., DEMOCOPHES, consortium, KolossaGehring, M., 2014. A systematic approach for designing a HBM Pilot Study for Europe. Int. J. Hyg. Environ. Health 217 (2-3), 312-322. http://dx.doi.org/ 10.1016/j.ijheh.2013.07.004

Bellanger, M., Pichery, C., Aerts, D., Berglund, M., Castaño, A., Cejchanová, M. Crettaz, P., Davidson, F., Esteban, M., Fischer, M.E., Gurzau, A.E., Halzlova, K. Katsonouri, A., Knudsen, L.E., Kolossa-Gehring, M., Koppen, G., Ligocka, D., Miklavčič, A., Reis, M.F., Rudnai, P., Tratnik, J.S., Weihe, P., Budtz-Jørgensen, E., Grandjean, P., DEMO/COPHES, 2013. Economic benefits of methylmercury exposure control in Europe: monetary value of neurotoxicity prevention. Environ. Health 7 (12), 3. http://dx.doi.org/10.1186/1476-069X-12-3.

Blair, A., Saracci, R., Vineis, P., Cocco, P., Forastiere, F., Grandjean, P., Kogevinas, M. Kriebel, D., McMichael, A., Pearce, N., Porta, M., Samet, J., Sandler, D.P., Costantini, A.S., Vainio, H., 2009. Epidemiology, public health, and the rhetoric of false positives. Environ. Health Perspect. 117 (12), 1809-1813. http://dx.doi.org/ 10.1289/ehp.0901194.

Casteleyn, L., Dumez, B., Jamers, A., Van Damme, K., 2010. Ethics and data protection in human biomarker studies in environmental health. ISBN: 978-83-60818-435, pp. 118.

Casteleyn, L., Van Tongelen, B., Reis, MF., Polcher, A., Joas, R., 2007. Human biomonitoring: towards more integrated approaches in Europe (Editorial). Int. J. Hyg. Environ.-Health 210, 199-200.

Calafat, A., 2012. The U.S. National Health and Nutrition Examination Survey and human exposure to environmental chemicals. Int. J. Hyg. Environ. Health 215, 2, 99-101.

Cerná, M., Krsková, A., Cejchanová, M., Spěváčková, V., 2012. Human biomonitoring in the Czech Republic: an overview. Int. J. Hyg. Environ. Health 215 (2), 109-119.

Cerná, M., Spěvácková, V., Batáriová, A., Smíd, J., Cejchanová, M., Ocadlíková, D., Bavorová, H., Benes, B., Kubínová, R., 2007. Human biomonitoring system in the Czech Republic. Int. J. Hyg. Environ. Health 210(3-4), 495-499 (Epub 2007 February 12)

Conrad, A., Seiwert, M., Hünken, A., Quarcoo, D., Schlaud, M., Groneberg, D., 2013. The German Environmental Survey for Children (GerES IV): reference values and distributions for time-location patterns of German children. Int. J. Hyg. Environ. Health 216 (1), 25-34. doi: 10.1016/j.ijheh.2012.02.00 (Epub 2012 March 10)

Cyprus Presidency Conference, 'Human Biomonitoring: Linking Environment to Health and Supporting Policy', Larnaca, October 23-24, 2012. 〈http://www. cy2012.eu/index.php/en/news-categories/press-

release-european-projects-measure-chemicals-in-people-across-eur ope-for-the-first-time $>$ (accessed 08.04.14).

Den Hond, E., Govarts, E., Willems, H., Smolders, R., Casteleyn, L., Kolossa-Gehring M., Schwedler, G., Seiwert, M., Fiddicke, U., Castaño, A., Esteban, M., Angerer, J., Koch, H.M., Schindler, B.K., Sepai, O., Exley, K., Bloemen, L., Horvat, M., Knudsen, L.E., Joas, A., Joas, R., Biot, P., Aerts, D., Koppen, G., Katsonouri, A., Hadjipanayis, A., Krskova, A., Maly, M., Mørck, T.A., Rudnai, P., Kozepesy, S., Mulcahy, M. Mannion, R., Gutleb, A.C., Fischer, M.E., Ligocka, D., Jakubowski, M., Reis, M.F., Namorado, S., Gurzau, A.E., Lupsa, I.R., Halzlova, K., Jajcaj, M., Mazej, D., Snoj Tratnik, J., López, A., Lopez, E., Berglund, M., Larsson, K., Lehmann, A., Crettaz, P., Schoeters, G. 2014. First steps toward harmonized human biomonitoring in
Europe: demonstration project to perform human biomonitoring on a European scale. Environ. Health Perspect., 123(3):255-263 (2015); http://dx.doi. org/10.1289/ehp.1408616.

ECETOC (European Centre for Ecotoxicology and Toxicology of Chemicals), 2005 Guidance for the interpretation of biomonitoring data. Doc no. 44. Brussel, Belgium.

Egorov, A., October 22-25, 2012. Developing an HBM survey for assessing progress towards goals set in the Parma Declaration. In: Proceedings of Human Biomonitoring (HBM) - Linking Environment to Health and Supporting Policy, Larnaca, Cyprus, p. 43.

Esteban M, Schindler BK, Jiménez-Guerrero JA, Koch HM, Angerer J, Rivas TC, Rosado M, Gómez S, Casteleyn L, Kolossa-Gehring M, Becker K, Bloemen L, Schoeters G, Hond ED, Sepai O, Exley K, Horvat M, Knudsen LE, Joas A, Joas R, Aerts D, Biot P, Borošová D, Davidson F, Dumitrascu I, Fisher ME, Grander M, Janasik B, Jones K, Kašparová L, Larssen T, Naray M, Nielsen F, Hohenblum P, Pinto R, Pirard C, Plateel G, Tratnik J, Wittsiepe J, Castaño A, Equas Reference Laboratories, 2014. Mercury analysis in hair: Comparability and quality assessment within the transnational COPHES/DEMOCOPHES project. Environmental Research, this issue, 2014 Dec 4. pii: S0013-9351(14)00429-0. http://dx. doi.org/10.1016/j.envres.2014.11.014. [Epub ahead of print].

European Commission, European environment and health strategy of 11 June 2003 [COM(2003) 338 final. 〈http://europa.eu/legislation_summaries/environment/ general_provisions/128133_en.htm〉 (accessed 08.04.14).

European Commission, Communication from the Commission to the Council, the European Parliament, the European Economic and Social Committee. The European Environment \& Health Action Plan 2004-2010. Brussels, 9.6.2004. COM (2004) 416 final.

European Union, 1976. Council Directive 76/768/EEC of 27 July 1976 relating to cosmetic products.

European Union, 1998. Council Directive 98/24/EC of 7 April 1998 on the protection of the health and safety of workers from the risks related to chemical agents at work.

Ewers, U., Krause, C., Schulz, C., Wilhelm, M., 1999. Reference values and human biological monitoring values for environmental toxins. Report on the work and recommendations of the Commission on Human Biological Monitoring of the German Federal Environmental Agency. Int. Arch. Occup. Environ. Health 72, $255-260$.

Fiddicke, U., Becker K., Schwedler, G., Seiwert, M., Joas, R., Joas, A., Biot, P, Aerts, D. Casteleyn, L., Dumez, D., Castaño, A., Esteban, M., Angerer, J., Koch, H.M., Schoeters, G., Den Hond, E., Sepai, O., Exley, K., Knudsen, L.E., Horvat, M., Bloemen, L., Katsonouri, A., Hadjipanayis, A., Cerna, M., Krsková, A., Jensen, A.F., Nielsen, F., Rudnai, P., Közepésy, S., Gutleb, A.C., Fischer, M.E., Ligocka, D., Kamińska, J., Reis, F.M., Namorado, S., Lupsa, I.R., Gurzau, A.G., Halzlová, K., Mazej, D., Snoj Tratnik, J., Rivas, T.C., Gómez, S., Berglund, M., Larsson, K., Lehmann, A., Crettaz, P., Dewolf, M.C., Burns, D., Kellegher, A., Kolossa-Gehring, M., 2014 Lessons learnt on recruitment and fieldwork from a pilot European human biomonitoring survey. Environmental Research, this issue. http://dx.doi.org/10. 1016/j.envres.2014.08.039i.

Fillol, C., Garnier, R., Mullot, J.U., Boudet, C., Momas, I., Salmi, L.R., Vandentorren, S., 2014. Prioritization of the biomarkers to be analyzed in the French biomonitoring program. Biomonitoring 1, 95-104.

Fréry, N., Vandentorren, S., Etchevers, A., Fillol, C., 2012. Highlights of recent studies and future plans for the French human biomonitoring (HBM) programme. Int. J. Hyg. Environ. Health 215 (2), 127-132.

Gallo, V., Egger, M., McCormack, V., Farmer, P.B., Ioannidis, J.P., Kirsch-Volders, M., Matullo, G., Phillips, D.H., Schoket, B., Stromberg, U., Vermeulen, R., Wild, C., Porta, M., Vineis, P., 2011. STrengthening the Reporting of OBservational studies in Epidemiology - Molecular Epidemiology (STROBE-ME): an extension of the STROBE Statement. PLoS Med 8 (10), e1001117. http://dx.doi.org/10.1371/journal.pmed.1001117.

Haines, D.A. Murray, J. 2012. Human biomonitoring of environmental chemicals early results of the 2007-2009 Canadian Health Measures Survey for males and females. Int. J. Hyg. Environ. Health 215, 2.

Halkoaho, A., Vähäkangas, K., Häggman-Laitila, A., Pietilä, A.M., 2012. Views of midwives about ethical aspects of participation in placental perfusion studies. Midwifery 28 (1), 131-137.

Horvat, M., Mazej, D., Snoj Tratnik, J., Kononenko, L., Lapanja, S., Kobal, A.B., Krsnik, M., Osredkar, J., 2012. A legal framework for HBM: experiences in Slovenia. Proceedings of Human Biomonitoring (HBM) - Linking Environment to Health and Supporting Policy, October 22-25, 2012, Larnaca, Cyprus, pp. 43

Exley, K., Cano, N., Aerts, D., Biot, P., Casteleyn, L., Kolossa-Gehring, M., Schwedler G., Castaño, A., Angerer, J., Koch, H.M., Esteban, M., Schoeters, G., Den Hond, E., Horvat, M., Bloemen, L., Knudsen, L.E., Joas, R., Joas, A., Dewolf, M.-C., Van de Mieroop, E., Katsonouri, A., Hadjipanayis, A., Cerna M., Krskova, A., Becker, K. Fiddicke, U., Seiwert, M., Mørck, T. A., Rudnai, P., Kozepesy, S., Cullen, E., Kellegher, A., Gutleb, A.C., Fischer, M.E., Ligocka, D., Kamińska, J., Namorado, S., Fátima Reis, M., Lupsa, I.-R., Gurzau, A.E., Halzlova, K., Jajcaj, M., Mazej, D., Snoj Tratnik, J., Rivas, T.C., López, E., Berglund, M., Larsson, K., Sepai, O., 2014. Communication in a human biomonitoring study: focus group work, public engagement and lessons learnt in 17 European countries. Environ. Res., this issue, http://dx.doi.org/10.1016/j.envres.2014.12.003 [Epub aheadofprint].

Khoury, M.J., Lam, T.K., Ioannidis, J.P., Hartge, P., Spitz, M.R., Buring, J.E., Chanock, S. J., Croyle, R.T., Goddard, K.A., Ginsburg, G.S., Herceg, Z., Hiatt, R.A., Hoover, R.N., Hunter, D.J., Kramer, B.S., Lauer, M.S., Meyerhardt, J.A., Olopade, O.I., Palmer, J. R., Sellers, T.A., Seminara, D., Ransohoff, D.F., Rebbeck, T.R., Tourassi, G., Winn, D. 
M., Zauber, A., Schully, S.D., 2013. Transforming epidemiology for 21st century medicine and public health. Cancer Epidemiol. Biomark. Prev. 22 (4), 508-516.

Kolossa-Gehring, M., Becker, K., Fiddicke, U., Schulz, C., Conrad, A., Schröter-Kermani, C., Seiwert, M., 2011. Biomonitoring as a key tool in environmental health, the German approach. 〈http://www.milieu-en-gezondheid.be/resultaten/ 2007-2011/studiedag 21-12-2011/abstract MK.pdf (accessed 08.04.14).

Kolossa-Gehring, M., Becker, K., 2011. German initiative to support human biomonitoring: co-operation project between the german chemical industry association and the federal ministry for the environment, nature conservation and nuclear safety. Epidemiology 22 (1), S35.

Kuulasmaa, K., Tolonen, H., Koponen, P., Kilpeläinen, K., Avdicová, M., Broda, G., Calleja, N., Dias, C., Gösswald, A., Kubinova, R., Mindell, J., Männistö, S., Palmieri, L., Tell, G.S., Trichopoulou, A., Verschuren, W.M., 2012. An overview of the European health examination survey pilot joint action. Arch. Public Health 70 (1), 20. http://dx.doi.org/10.1186/0778-7367-70-20.

Miller, L., 2009. Common consent (Editorial). Nature 460 (7258), 933.

Morello-Frosch, R., Green Brody, J., Brown, P., Gasior Altman, R., Rudel, R.A., Pérez, C., 2009. Toxic ignorance and right-to-know in biomonitoring results communication: a survey of scientists and study participants. Environ. Health 8, 6 .

Morello-Frosch, R., Varshavsky, J., Liboiron, M., Brown, P., Brody, J.G., 2015. Communicating results in post-Belmont era biomonitoring studies: Lessons from genetics and neuroimaging research. Environmental Research 136, 363-372 10. 1016/j.envres.2014.10.001.

National Research Council of the National Academies, 2006. Human Biomonitoring for environmental chemicals, Committee on Human Biomonitoring for Environmental Toxicants, Board on Environmental Studies and Toxicology, Division on Earth and Life Studies. The National Academies Press, Washington DC.

Pérez-Gómez, B., Pastor-Barriuso, R., Cervantes-Amat, M., Esteban, M., Ruiz-Moraga, M., Aragonés, N., Pollán, M., Navarro, C., Calvo, E., Román, J., López-Abente, G., Castaño, A., 2012. BIOAMBIENT.ES study protocol: rationale and design of a cross-sectional human biomonitoring survey in Spain. Environ. Sci. Pollut. Res. $11 / 2012$ (2), 1193-1202.

Rappaport, S.M., 2012. Biomarkers intersect with the exposome. Biomarkers 17 (6), 483-489, http://dx.doi.org/10.3109/1354750X.2012.691553.

Schindler, B.K., Esteban, M., Koch, H.M., Castaño, A., Koslitz, S., Cañas, A., Casteleyn, L., Kolossa-Gehring, M., Schwedler, G., Schoeters, G., Den Hond, E., Sepai, O., Exley, K., Bloemen, L., Horvat, M., Knudsen, L.E., Joas, A., Joas, R., Biot, P., Aerts, D., Lopez, A., Huetos, O., Katsonouri, A., Maurer-Chronakis, K., Kasparova, L., Vrbík, K., Rudnai, P., Naray, M., Guignard, C., Fischer, M., Ligocka, D., Janasik, B., Reis, F.M., Namorado, S., Pop, C., Dumitrascu, I., Halzlova, K., Fabianova, E., Mazej, D., Snoj Tratnik, J., Berglund, M., Jönsson, B., Lehmann, A., Crettaz, P., Frederiksen, H., Nielsen, F., McGrath, H., Nesbitt, I., De Cremer, K., Vanermen, G., Koppen, G., Wilhelm, M., Becker, K., Angerer, J., 2014. The European COPHES/ DEMOCOPHES project: towards transnational comparability and reliability of human biomonitoring results. Int. J. Hyg. Environ. Health, http://dx.doi.org/ 10.1016/j.ijheh.2013.12.

Schoeters, G., Colles, A., Den Hond, E., Croes, K., Vrijens, J., Baeyens, W., Nelen, V., Van De Mieroop, E., Covaci, A., Bruckers, L., Van Larebeke, N., Sioen, I., Morrens, B., Loots, I., 2011. The Flemish Environment and Health Study (FLEHS) - Second Survey (2007-2011): Establishing Reference Values for Biomarkers of Exposure in the Flemish Population. In: Knudsen, L., Merlo., D.F. (Eds.), Biomarkers and Human Biomonitoring volume 1: ongoing programs and exposures. The Royal Society of Chemistry, UK, pp. 135-165.

Schulz, C., Wolf, U., Becker, K., Conrad, A., Hünken, A., Lüdecke, A., Müssig-Zufika, M., Riedel, S., Seiffert, I., Seiwert, M., Kolossa-Gehring, M., 2007. [German
Environmental Survey for Children (GerES IV) in the German Health Interview and Examination Survey for Children and Adolescents (KiGGS). First results] [Article in German]. Bundesgesundheitsblatt Gesundheitsforschung Gesundheitsschutz 50 (5-6) 889-894.

Smith, M.T., Vermeulen, R., Li, G., Zhang, L., Lan, Q., Hubbard, A.E., Forrest, M.S., McHale, C., Zhao, X., Gunn, L., Shen, M., Rappaport, S.M., Yin, S., Chanock, S. Rothman, N., 2005. Use of 'Omic' technologies to study humans exposed to benzene. Chem. Biol. Interact. 153-154, 123-127.

Smolders, R., Koppen, G., Schoeters, G., 2008. Translating biomonitoring data into risk management and policy implementation options for a European Network on Human Biomonitoring. Environ. Health 7 (Suppl. 1), S2. http://dx.doi.org/ 10.1186/1476-069X-7-S1-S2.

Smolders, R., Den Hond, E., Koppen, G., Govarts, E., Willems, H., Casteleyn, L., Kolossa-Gehring, M., Fiddicke, U., Castaño, A., Koch, H.M., Angerer, J., Esteban, M., Sepai, O., Exley, K., Bloemen, L., Horvat, M., Knudsen, L.E., Joas, A., Joas, R., Biot P., Aerts, D., Katsonouri, A., Hadjipanayis, A., Cerna, M., Krskova, A., Schwedler G., Seiwert, M., Nielsen, J.K.S., Rudnai, P., Közepesy, S., Evans, D.S., Ryan, M.P., Gutleb, A.C., Fischer, M.E., Ligocka, D., Jakubowski, M., Reis, M.F., Namorado, S., Lupsa, I.-R., Gurzau, A.E., Halzlova, K., 2014. Interpreting biomarker data from the COPHES/DEMOCOPHES twin projects: Using external exposure data to understand bio- marker differences among countries. Environ. Res., this issue, http://dx.doi.org/10.1016/j.envres.2014.08.016i.

Snoj Tratnik J, Mazej D, Horvat M (2012). Human biomonitoring studies in Slovenia - toxic metals, arsenic and essential elements. A legal framework for HBM: experiences in Slovenia. Proceedings of "Human Biomonitoring (HBM) - Linking Environment to Health and Supporting Policy", Larnaca, Cyprus, p. 88

Stokstad, E., 2004. Biomonitoring. Pollution gets personal. Science. 304 (5679), 1892-1894

Vineis, P., Perera, F., 2007. Molecular epidemiology and biomarkers in etiologic cancer research: the new in light of the old. Cancer Epidemiol. Biomarkers Prev. 16 (10), 1954-1965.

Vineis, P., Chuang, S.C., Vaissière, T., Cuenin, C., Ricceri, F., Genair-EPIC Collaborators Johansson, M., Ueland, P., Brennan, P., Herceg, Z., 2011. DNA methylation changes associated with cancer risk factors and blood levels of vitamin metabolites in a prospective study. Epigenetics 6 (2), 195-201.

Viso, A.C., Casteleyn, L., Biot, P., Eilstein, D., 2009. Human biomonitoring programmes and activities in the European Union. J. Epidemiol. Commun. Health 63, 623-624. http://dx.doi.org/10.1136/jech.2008.083709.

Weuve, J., Yanosky, J.D., 2012. Polycyclic aromatic hydrocarbons, particulate air pollution, and cognitive decline-reply. Arch. Intern. Med. 172 (13), 1045-1046. http://dx.doi.org/10.1001/archinternmed.2012.2159.

WHO, Parma Declaration on Environment and Health, 2010. EUR/55934/5.1 Rev. 2 11 March 2010.

Wild, C.P. 2005. Complementing the genome with an "exposome": the outstanding challenge of environmental exposure measurement in molecular epidemiology. Cancer Epidemiol. Biomark. Prev. 14 (8), 1847-1850.

Wild, C.P., 2011. Future research perspectives on environment and health: the requirement for a more expansive concept of translational cancer research. Environ. Health 10 (Suppl. 1), S15 (5).

Willett, W.C., 2002. Balancing life-style and genomics research for disease prevention. Science 296 (5568), 695-698. 